\title{
Can medical staff have visible tattoos? A survey study among students
}

\author{
Anna Paprocka-Lipińska1 ${ }^{\oplus}$, Alan Majeranowski1 ${ }^{\circledR}$, Małgorzata \\ Drozd-Garbacewicz¹ ${ }^{\odot}$, Małgorzata Mazanek², Maria Hebdzińska², \\ Joanna Styszko ${ }^{2}$
}

${ }^{1}$ Department of Ethics, Medical University of Gdańsk, Poland

${ }^{2}$ Students Circle of Bioethics, Department of Ethics, Medical University of Gdańsk,Poland

\begin{abstract}
Background: Tattoo is becoming a more and more common form of body decoration of people from representatives of various professions. The aim of this study was: what is the opinion of university students about medical staff having visible tattoos. Material and methods: The study was conducted among the students of four universities in Gdańsk. The questionnaire contained questions about the acceptance of visible tattoos in people working in medical professions. The respondents were also asked about their attitudes to tattoos as a form of body decoration and whether they had tattoos themselves. The statistical analysis was performed using IBM SPSS Statistics 25 software. Results: Filled-in questionnaires were obtained from 676 respondents, including 477 students of the medical university and 199 students of non-medical universities. The students who have tattoos themselves accept visible tattoos in healthcare professionals to a significantly greater extent (92\%) than those who do not have tattoos, but the acceptance of visible tattoos in healthcare professionals in this group turned out to be very high too (75\%). The respondents most readily accepted a visible tattoo on the skin of a laboratory diagnostician (75\%). Conclusions: University students, regardless of their university profile, consider a visible tattoo as a completely acceptable phenomenon in healthcare professionals.
\end{abstract}

Keywords: health care professionals $\cdot$ visible tattoos $\cdot$ dress code

\section{Citation}

Paprocka-Lipińska A, Majeranowski A, Drozd-Garbacewicz M, Mazanek M, Hebdzińska M, Styszko J.

Can medical staff have visible tattoos? A survey study among students

Eur J Transl Clin Med. 2019;2(2):23-26.

DOI: $10.31373 /$ ejtcm/113511

Corresponding author:

Anna Paprocka-Lipińska, Department of Ethics, Medical University of Gdańsk, Poland

e-mail: anna.paprocka-lipinska@gumed.edu.pl

No external funds.

Available online: www.ejtcm.gumed.edu.pl

Copyright ${ }^{\circledR}$ Medical University of Gdańsk

This is Open Access article distributed under the terms of the Creative Commons Attribution-ShareAlike 4.0 International. 


\section{Introduction}

Tattoo, defined as intentional and permanent skin pigmentation, is becoming a more and more common phenomenon in the public space. According to an epidemiological study from 2015, the incidence of tattoos among the inhabitants of industrialised countries which indicate that approximately $30 \%$ of the adult population has at least one tattoo [1]. While in the past tattoos were mainly a form of expression of belonging to a subculture or social group, today they have become a vivid form of body decoration. Recently, having a tattoo has become a common phenomenon in various social groups and professions, including healthcare.

\section{Aim}

The aim of the study was to find out what is the opinion of university students about people working in medical professions having visible tattoos that cannot be easily covered with clothes (on the face, neck and hands).

\section{Material and methods}

A survey was conducted among the students of four universities in Gdańsk: the Medical University of Gdańsk, Stanislaw Moniuszko Academy of Music in Gdańsk, Gdańsk University of Technology and the University of Gdańsk. The self-administered questionnaire consisted of questions about the acceptance of medical professionals having visible tattoos. The respondents were also asked about their attitudes to tattoos as a form of body decoration and whether they had tattoos themselves. The study was approved by the Independent Bioethics Committee for Scientific Research of the Medical University of Gdańsk (approval no. NKBBN/724/2018-2019).

The statistical analysis was performed using IBM SPSS Statistics 25 software. The data was analysed using statistical description and comparison of subgroup results with chi-square test (comparison of proportions). The assumed probability value was $p<$ 0.05 , which means that the differences between the compared groups were considered as statistically significant if the $p$-value was smaller than 0.05 .

\section{Results}

A completed questionnaires were obtained from 676 respondents, including 477 students of the me- dical university and 199 students of the non-medical universities. The majority of them were women: $77 \%$ among the medical university respondents and $83 \%$ among the non-medical university respondents.

In total, $21 \%$ of the respondents confirmed having a tattoo. Majority of them were women ( $23 \%$ vs. men $12 \%$ ) from the non-medical universities ( $31 \%$ vs. medical university $17 \%)$.

Surprisingly, $64 \%$ of the students responded affirmatively to the question whether medical staff should follow some kind of a dress code. The affirmative responses were significantly more common among the students of the medical university than among the non-medical students from the ( $67 \%$ vs. $55 \%, p<0.05)$. The analysis of the responses to the question "do you find tattoos an attractive form of body decoration?" shows that $69 \%$ of the respondents consider this form of body decoration as attractive, with affirmative responses significantly more frequent among the students of the non-medical universities (75\% vs. $66 \%$, $\mathrm{p}<0.05)$. A statistically significant difference was observed also between the male and female respondents. Female students answered the question affirmatively more often than males ( $71 \%$ vs. $60 \%, p<0.05)$. The negative answer to this question was chosen by $16 \%$ of the respondents, significantly more frequently by the medical university students $(19 \%)$ than by those studying at the non-medical universities $(9 \%, p<0.05)$.

Asked about their acceptance of healthcare professionals having visible tattoos, $79 \%$ of the respondents answered affirmatively. The affirmative answer was chosen significantly more often by the non-medical university students ( $84 \%$ vs. $76 \%$ for the medical university students, $\mathrm{p}<0.05)$.

The data about the acceptance of particular medical professionals having visible tattoos is presented in Table 1. According to our study participants, visible tattoos are the most acceptable on laboratory diagnosticians, followed by nurses, dentists and physicians. The students were most reluctant to accept clinical psychologists with visible tattoos.

The respondents who have tattoos themselves were more reluctant to express limitations for the external appearance of healthcare professionals while the respondents who do not have tattoos were more restrictive in the topic (51\% vs. $67 \%$ for limitations in the external appearance, which is statistically significant, $p<0.05)$. Similarly, the students who have tattoos themselves accept visible tattoos in healthcare professionals to a significantly greater extent (92\%) than those who do not have tattoos ( $p<0.05)$. However, the acceptance of visible tattoos in healthcare professionals in the latter group also turns out to be quite high (75\%). 
Table 1. Responses to the question "in your opinion, can healthcare professionals listed below have visible tattoos?"

\begin{tabular}{|c|c|c|c|}
\hline & NO & $\begin{array}{c}\text { It does } \\
\text { not matter }\end{array}$ & YES \\
\hline $\begin{array}{c}\text { Clinical } \\
\text { psychologist }\end{array}$ & $16.9 \%$ & $19.8 \%$ & $63.3 \%$ \\
\hline Physican & $14.8 \%$ & $19.8 \%$ & $65.4 \%$ \\
\hline Nurse & $14.6 \%$ & $19.1 \%$ & $66.3 \%$ \\
\hline Dentist & $13.5 \%$ & $18.8 \%$ & $67.8 \%$ \\
\hline Paramedic & $10.1 \%$ & $19.2 \%$ & $70.7 \%$ \\
\hline $\begin{array}{c}\text { Physical } \\
\text { therapist }\end{array}$ & $8.6 \%$ & $19.4 \%$ & $72.0 \%$ \\
\hline $\begin{array}{c}\text { Pharmacist } \\
\text { diagnostician }\end{array}$ & $8.4 \%$ & $20.3 \%$ & $71.3 \%$ \\
\hline \begin{tabular}{c} 
Dietician \\
\hline
\end{tabular} & $5.2 \%$ & $22.2 \%$ & $72.6 \%$ \\
\hline
\end{tabular}

\section{Discussion}

Tattoo, that is intentional permanent skin pigmentation using exogenous substances, dates back to about 3,000 years BC, and became popular in Western Europe after the travellers' expeditions of the $17^{\text {th }}$ century [2]. In the past, tattoo had (and probably may still have) significant symbolic meaning in certain social groups (e.g. prisoners or the lower class) [3]. Recently, tattooing has become increasingly popular, fashionable and a form of artistic expression. According to the estimations, approximately $20-30 \%$ of adults from the industrialised countries of the Western Europe have at least one tattoo [4]. In our study, the fact of having a tattoo was confirmed by $31 \%$ of students from the non-medical universities and $17 \%$ of students from the medical university, which corresponds with literature data, for example with the paper by Rogowska et al. about the level of knowledge about tattoo-related complications in university students in the Tricity agglomeration [5].

Numerous scientific publications have attempted to answer the questions why such a great (and still increasing) number of people of various educational and professional backgrounds decides on permanent, invasive skin pigmentation and what are the possible consequences of it. Kluger et al. lists 6 categories of motivations for having a tattoo, indicating that two of them (tattoos as a form of body decoration and to emphasize one's individualism) are most common in adults [1]. Similar motivations are indicated in a review article about tattoos in women and their health implications during pregnancy, labour and breastfeeding [4].

The increasing popularity of tattoos inspires also a reflection on how people with a visible tattoo are perceived by the society. Stuppy et al. concluded that a visible tattoo in a patient may be the cause of negative perception of this patient by medical staff and students of medicine [6]. Moreover, Ellis showed that stereotypical perceptions of people with tattoos still exist, which leads to some limitations, e.g. potential employers stated that having a visible tattoo may be the cause of a job candidate's rejection [7].

Other studies were devoted to the patients' perception of healthcare professionals with visible tattoos and piercings. The results of some earlier research clearly show that patients have negative attitudes, e.g. perceive nurses with tattoos as less professional and less competent [8]. Similar results have been obtained for physicians with nose or lip rings [9]. However, in a paper about the perception of the emergency room doctors Cohen et al. concluded that having a visible tattoo or piercing does not influence the perception of medical staff by emergency room patients [10]. The publication caused a heated debate in the Internet, which shows that a visible tattoo in people employed by the healthcare system seems to be fully acceptable by patients, and in some cases it may even be useful for starting the patient-doctor relationship [11-14].

An Scottish study conducted in 2018 showed that physicians with visible tattoos are perceived negatively both by medicine students and other physicians [15]. It was also noted that there are no provisions or regulations regarding the issue and that there is a need for discussion about the limitations in the expression of one's own individuality in medical professions.

The results of our study indicate high tolerance among both medical and non-medical university students for tattoos in healthcare professionals, regardless of what their own preferences are and whether they have tattoos themselves. It must be stressed that hitherto there are no limitations concerning the physical appearance of healthcare professionals, although there may be some local regulations in particular healthcare centres. The Polish Medical Ethics Code mentions only the need to represent the profession with dignity and that 'physicians cannot promote unhealthy 
attitudes, also outside their professional work' [16]. As tattoo may be linked to a risk of infections or allergic reactions, having a visible tattoo may be questionable from this point of view.

\section{Conclusions}

1. Regardless of their field of study, university students consider it completely acceptable for healthcare professionals to have a visible tattoo, but they simultaneously state that such professionals should be subjected to some rules as to their physical appearance (dress code).
2. Medical university students seem slightly more conservative in their opinions about the limitations in the appearance of medical staff. However, their acceptance of visible tattoos on healthcare professionals is still high (although lower than of students of non-medical universities).

3. The students who do not like tattoos as a form of body decoration and do not have tattoos themselves, are still quite liberal when it comes to visual tattoos in healthcare professionals. However, they express their acceptance significantly less frequently than students who like tattoos or have a tattoo themselves.

\section{References}

1. Kluger N. Epidemiology of tattoos in industrialized countries. In: Current Problems in Dermatology [Internet]. 2015. p. 6-20. Available from: https://www.karger.com/DOI/10.1159/000369175

2. Pesapane F, Nazzaro G, Gianotti R, Coggi A. A short history of tattoo. JAMA dermatology [Internet]. 2014;150(2):145. Available from: https://doi.org/10.1001/jamadermatol.2013.8860

3. Klein CA, Kenedi C. Understanding Tattoos in Medicolegal Assessments. J Am Acad Psychiatry Law [Internet]. 2018;46(1):93101. Available from: https://europepmc.org/abstract/med/29618541

4. Farley CL, Van Hoover C, Rademeyer C. Women and tattoos: fashion, meaning, and implications for health. J Midwifery Womens Health [Internet]. 2019;64(2):154-69. Available from: https://doi.org/10.1111/jmwh.12932

5. Rogowska P, Szczerkowska-Dobosz A, Kaczorowska R, Słomka J, Nowicki R. Tattoos: Evaluation of knowledge about health complications and their prevention among students of Tricity universities. J Cosmet Dermatol [Internet]. 2018;17(1):2732. Available from: https://doi.org/10.1111/jocd.12479

6. Stuppy DJ, Armstrong ML, Casals-Ariet C. Attitudes of health care providers and students towards tattooed people. J Adv Nurs [Internet]. 1998;27(6):1165-70. Available from: https://doi.org/10.1046/j.1365-2648.1998.00626.x

7. Ellis AD. A picture is worth one thousand words: Body art in the workplace. Empl Responsib Rights J [Internet]. 2015;27(2):101-13. Available from: https://doi.org/10.1007/s10672-014-9254-1

8. Westerfield H V, Stafford AB, Speroni KG, Daniel MG. Patients' perceptions of patient care providers with tattoos and/or body piercings. JONA J Nurs Adm [Internet]. 2012;42(3). Available from: https://doi.org/10.1097/NNA.0b013e31824809d6

9. Newman AW, Wright SW, Wrenn KD, Bernard A. Should physicians have facial piercings? J Gen Intern Med [Internet]. 2005;20(3):213-8. Available from: $\underline{\text { http://link.springer.com/10.1111/i.1525-1497.2005.40172.x }}$

10. Cohen M, Jeanmonod D, Stankewicz H, Habeeb K, Berrios M, Jeanmonod R. An observational study of patients' attitudes to tattoos and piercings on their physicians: the ART study. Emerg Med J [Internet]. 2018 Sep;35(9):538-43. Available from: http://emj.bmj.com/lookup/doi/10.1136/emermed-2017-206887

11. Houston M. Would you care if your doctor had a 'Mad Max' tattoo? [Internet]. The Irish times. 2018 [cited 2019 Nov 4]. Available from: https://www.irishtimes.com/life-and-style/health-family/would-you-care-if-your-doctor-had-a-mad-maxtattoo-1.3553635

12. Foston N. Should doctors show their tattoos at work? DOs speak out - The DO [Internet]. The Do. 2018 [cited 2019 Nov 4]. Available from: https://thedo.osteopathic.org/2018/11/should-doctors-show-their-tattoos-at-work-dos-speak-out/

13. Kalaichandran A. Do patients care if their doctors have tattoos or piercings? - ABC News [Internet]. ABC News. 2018 [cited 2019 Nov 4]. Available from: https://abcnews.go.com/health/patients-care-doctors-tattoos-piercing/story?id=56329779

14. Bernard MA. Will that tattoo hurt you professionally? Not if you're a doctor, study finds [Internet]. Philadelphia Inquirer. 2018 [cited 2019 Nov 4]. Available from: https://www.inquirer.com/philly/health/how-do-patients-perceive-doctorswith-tattoos-20180709.html

15. Callaghan B, McConville K. The tattooed doctor: An exploration of the perceptions of medical students and medical school staff. MedEdPublish [Internet]. 2018;7(1):49. Available from: https://doi.org/10.15694/mep.2018.0000049.1

16. Polish Medical Ethics Code, uniform text of 2 January 2004, with the amendmends passed on 20 September 2003. In: 7th Extraordinary National Medical Congress. Warsaw; 2004. 